Editorial

\title{
Resumed Publication of Pharmaceuticals in 2009
}

\section{Shu-Kun Lin and Derek J. McPhee}

Molecular Diversity Preservation International (MDPI), Kandererstrasse 25, Basel CH-4057, Switzerland; Tel. ++41 79322 3379, Fax: ++41 61302 8918, E-mails: lin@mdpi.org; mcphee@mdpi.org

Received: 29 March 2009 / Published: 1 April 2009

After a five year hiatus, we are pleased to announce the resumption of publication of the MDPI journal Pharmaceuticals (ISSN 1424-8247). First launched in 2004, few suitable papers were submitted and only one was published [1], before our limited editorial resources at the time led us to temporarily discontinue publication. Several things have changed since then. First, there has been an explosive growth in the number of manuscripts submitted and published in MDPI's various current journals [2], whose topics clearly fall within the intended scope of Pharmaceuticals and we feel that these manuscripts merit a dedicated forum. Second, the expansion of MDPI, now with Editorial Offices and staff in Basel (Switzerland) and Beijing (China), allows us to provide Pharmaceuticals' authors with all the services they could desire and deserve: a simple manuscript submission process, rigorous peer review, quick revision turnaround, Open Access publication on a new and attractive platform and coverage by all the major abstracting services. In addition, a new Editorial Board comprised of noted academic and industry scientists has been set up for Pharmaceuticals. Finally, to better focus the subject matter published in Pharmaceuticals on molecular medicines, we have also set up a special section in International Journal of Molecular Sciences (IJMS, ISSN 1422-0067) for papers on nutraceuticals or chemopreventives. We look forward to receiving and publishing your papers and as always, we welcome your comments and suggestions.

\section{References and Notes}

1. Pauli, A.; Schilcher, H. Specific Selection of Essential Oil Compounds for Treatment of Children's Infection Diseases. Pharmaceuticals 2004, 1, 1-30.

2. http://www.mdpi.com.

(C) 2009 by the authors; licensee Molecular Diversity Preservation International, Basel, Switzerland. This article is an open-access article distributed under the terms and conditions of the Creative Commons Attribution license (http://creativecommons.org/licenses/by/3.0/). 